\title{
ARTICLE \\ Construction and Management of Micro-service Platform of Libraries in Universities and Colleges under the Circumstance of We-media
}

\section{Guojun Yu*}

Xiangyang Vocational and Technical College, Xiangyang, Hubei, 441050, China

\begin{tabular}{|c|c|}
\hline ARTICLE INFO & ABSTRACT \\
\hline Article history & \multirow{9}{*}{$\begin{array}{l}\text { This paper focuses on the in-depth study of construction and management } \\
\text { of micro-service platform of libraries in universities and colleges under } \\
\text { the circumstance of we-media, which mainly elaborates several opti- } \\
\text { mization measures through the problems existing in the construction of } \\
\text { micro-service platform of university libraries, for example, enriching the } \\
\text { content of micro-service platform, continuously improving the interactiv- } \\
\text { ity in the construction of micro-service platform, increasing publicity and } \\
\text { improving the level of technical management, etc., thereby promoting } \\
\text { the smooth construction of micro-service platform of libraries in univer- } \\
\text { sities and colleges, constantly improving the service level and ability of } \\
\text { libraries in universities and colleges, and obtaining high satisfaction from } \\
\text { readers. }\end{array}$} \\
\hline Received: 5 September 2019 & \\
\hline Revised: 17 September 2019 & \\
\hline Accepted: 9 October 2019 & \\
\hline Published Online: 16 October 19 & \\
\hline Keywords: & \\
\hline We-media & \\
\hline Libraries in universities and colleges & \\
\hline Micro-service platform & \\
\hline
\end{tabular}

\section{Introduction}

A fter the emergence of we-media era, WeChat (MicroMessage), MicroBlog, and MicroVideo have been widely used, which have become indispensable tools in people's daily life, and people's learning and lifestyle have undergone earth-shaking changes. Under the influence of various APPs on the mobile terminal, there are more advantages such as convenience and promptness in information push and acquisition. However, under the influence of some restrictive factors, some libraries in universities and colleges have not attached great importance to the development of we-media; therefore, the micro-services and micro-platform construction are still in a relatively lagging stage. Based on this, libraries in universities and colleges must constantly innovate service methods to meet the needs of readers to the greatest extent, and implement the micro-services and micro-service platform construction to provide a broader development space for libraries in universities and colleges.

\section{Analysis of the Feasibility Factors of the Construction of Micro-service Platform of Li- braries in Universities and Colleges under the Circumstance of We-media}

Under the influence of China's "Internet +" strategy, the development speed of mobile technology is extremely rapid, and the popularity of smart terminals has also risen to a new height. The development and application of various APPs has brought great convenience to readers' learning and life. Therefore, libraries in universities and colleges

*Corresponding Author:

Guojun Yu,

Xiangyang Vocational and Technical College, No. 18 Longzhong Road, Xiangcheng District, Xiangyang, Hubei, 441050, China; E-mail:425855126@qq.com. 
must be paid great attention, which should constantly innovate service models and service content, strengthen the construction of micro-service platform, and maximize the satisfaction of readers' needs, among which provide readers with personalized services, reflecting the service tenet of "people-oriented". ${ }^{[1]}$

At the same time, libraries in universities and colleges should further optimize and integrate the corresponding literature resources, such as mobile library, WeChat official accounts, MicroBlog, and MicroVideo, etc., so as to realize the "one-stop search service" to create convenient conditions, adapt to the changing trend of readers' needs, and upgrade own service capabilities and levels. In addition, with the construction of the micro-service platform, as an important basic data platform, it is also an important measure to build a smart campus to better solve the problem of information isolated island.

\section{The Shortcomings in the Construction of Micro-service Platform of Libraries in Universities and Colleges under the Circum- stance of We-media}

\subsection{The Content of the Micro-service Platform Is Relatively Simple}

At this stage, some libraries in universities and colleges only provide micro- newspapers, micro-videos and other services in the construction of micro-service platform. There is a great difference between the content of columns, and the need for featured service content has not been met, which is difficult to meet the needs of readers to a certain extent, and is not conducive to the smooth construction of micro-service platform of libraries in universities and colleges.

\subsection{A Serious Lack of Good Interactivity}

In the construction of the micro-service platform of libraries in universities and colleges, although there are many columns such as resource recommendation, notice announcement, etc., the column lacks good interaction. At the same time, although some libraries in universities and colleges have set up automatic message replying functions, they only respond and reply according to mechanically combined keywords, ${ }^{[2]}$ whose role of interaction and communication is not reflected.

\subsection{Less Communication Channels}

At this stage, some readers have not fully understood the construction situation of micro-service platform of libraries in universities and colleges. The reason for this phenomenon is mainly due to the lack of micro-service communication channels. In the process of publicity, only the form of the campus display board is used, and the publicity effect is difficult to guarantee. Although the micro-service platform provides great convenience for readers' inquiry and borrowing services, due to the lack of publicity, some readers still go to the library to inquire and borrow books.

\subsection{The Level of Technical Management Needs to Be Improved}

For the micro-service platform of libraries in universities and colleges, it has the duties of public service, book information push, etc. As everyone knows, the micro-service platform of libraries in universities and colleges belongs to a new service model. The level of technical management is relatively low, and some staff members have to improve their professional level of information technology and lack good problem-solving skills. Moreover, in the page design, there are only a few pictures, while voice and video technologies have not been integrated, which is difficult to fully exert the readers' reading interest, thereby hindering the construction of the micro-service platform of libraries in universities and colleges.

\section{Measures for Improvement in the Con- struction of Micro-service Platform of Li- braries in Universities and Colleges under the Circumstance of We-media}

\subsection{Enrich the Content of Micro-service Platform}

For the micro-service platform, it is an important component of the construction of the smart library. It must be combined with the actual needs of the readers to emphasize the highlights, strengthen the application of multiple service methods, and build a characteristic micro-service platform. The framework diagram of the micro-service platform of libraries in universities and colleges is shown in Figure 1.

In terms of construction content, it mainly includes basic business, core business and third-party business, specifically: The first is the basic business. In the basic business, it is open to all readers, so that readers can view the basic business in real time, whose information content mainly includes library overview, rules and regulations, news information and so on; the second is the core business. The core business content, including one-stop electronic resource search and download, seat reservation and online consultation, and has been widely used in reader community, ${ }^{[3]}$ which is an important way and method to 
improve the attention and use of micro-services; the last is the third-party business, which has a great impact on the reader's learning and life and is one of the important aids. Generally speaking, third-party services are mostly off-campus resources, mainly including remote databases and CNKI Reader. These services, driven by remote access, can make access unobstructed.

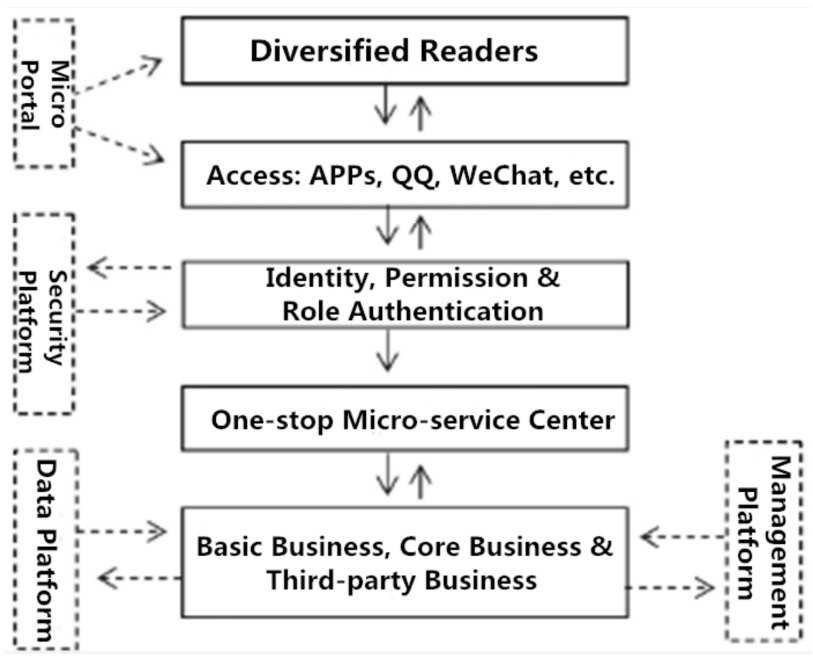

Figure 1. The framework diagram of the micro-service platform of libraries in universities and colleges

\subsection{Continuously Improve the Interactivity in the Construction of Micro-service Platform}

(1) After a large number of readers focus on the micro-service platform, it is necessary to strengthen the management of the micro-service platform. Moreover, much attention must be paid to the interactive usage experience to continuously improve the user adhesion of the micro-service platform of libraries in universities and colleges, and obtain higher satisfaction from the readers, and then improve the interaction in the construction of the micro-service platform.

For example, taking the Tsinghua University Library as an example, the library developed a binding interaction module in the public platform. Readers can use the constraint query instructions to obtain information such as library phone calls, lectures, personal borrowings, and popular academic literatures.

(2) After the new push article is issued, the manager should promptly reply to the background to check the article readings and comments, and strengthen communication and interaction with readers. On this basis, regular questionnaire survey activities will also be conducted to clarify the service orientation of the micro-service platform and ensure readers' good reading interest.

\subsection{Increase Publicity}

In the process of construction of micro-service platform of libraries in universities and colleges, good publicity and promotion are crucial. Firstly, the QR code of the public platform can be placed on the relevant website or webpage; secondly, the QR code can also be posted on the electronic screen and reading seats of the library; finally, in the library-related training and lectures, the corresponding promotion and recommendation can also be carried out. It is necessary to put the promotion of the construction of the micro-service platform of libraries in universities and colleges into place, ${ }^{[4]}$ in this way, more readers can be attracted to pay attention to it, and then the influence and popularity of the micro-service platform will be enhanced.

In addition, libraries in universities and colleges should also strengthen their specialized services and regularly carry out a series of special activities, such as reader interactions and lectures, which are pushed to readers in detail and guide readers to actively participate in these activities and this is also of great help to the promotion of the micro-service platform of libraries in universities.

\subsection{Improve the Level of Technical Management}

In the construction of micro-service platform of libraries in universities and colleges, the technical level is also one of the important construction contents, therefore, it is necessary to strengthen the application of modern technology, add books and information promotion content, and integrate interesting elements such as sound, video and animation to form an integrated dynamic picture, which will attract readers' attention. Generally speaking, libraries in universities and colleges have the characteristics of wide sources of information resources and rich content, so readers need to waste more time in the selection process, which has an impact on readers' reading enthusiasm to a certain extent, and the push effect is difficult to guarantee. Therefore, libraries must reasonably classify and integrate book resources, strengthen the construction of network navigation systems, and guide readers to select the information resources they need. Under the guidance of the windows, the reader can directly input the keywords to obtain the required information resources.

In addition, in the consulting service, it is necessary to strengthen the application of data mining technology, and by collecting and investigating the reader information, the reader's requirements can be understood, so as to determine the most suitable push content, and constantly improve the level of personalized service of libraries in universities and colleges, and obtain high recognition 
from readers.

\section{Conclusion}

In summary, under the circumstance of we-media, it is of vital importance to strengthen the construction of micro-service platform of libraries in universities and colleges, to promote the construction of libraries in universities and colleges to a new height and depth, and to bring a new experience to the learning and life for readers in universities and colleges.

\section{References}

[1] Jun Zhang, Lingshuang Liu, Jianan Liu. Investigation and analysis of MicroBlog service for libraries in universities and colleges in Beijing[J]. Electronic
Commerce, 2017(12):95-96. (in Chinese)

[2] Yujie Zhao, Wenbin Yao, Yuejian Yang, Yang Cui. Research on the optimization strategy of information push service of libraries in universities and colleges under the background of micro-communication era[J]. The Guide of Science \& Education, 2017(12):178-179. (in Chinese)

[3] Meitao Liu, Wenbin Liu. Research on the construction of a micro-innovation model of subject service based on user experience[J]. Researches in Library Science, 2017(20):67-71. (in Chinese)

[4] Meng Wang, Yiluan Li, Yong Zhang. Research on the new system and service model of university and college library subject resources under the mobile environment $[\mathrm{J}]$. Researches in Library Science, 2017(18):51-55. (in Chinese) 